\title{
Effectiveness of Tirobot-assisted vertebroplasty in treating thoracolumbar osteoporotic compression fracture
}

Boyao Wang ${ }^{\dagger}$, Jiang Cao ${ }^{\dagger}$, Jie Chang ${ }^{\dagger}$, Guoyong Yin, Weihua Cai, Qingqing Li, Zhenfei Huang, Lipeng Yu* and Xiaojian $\mathrm{CaO}^{*}$

\begin{abstract}
Background: Percutaneous kyphoplasty is the main method in the treatment of thoracolumbar osteoporotic compression fractures. However, much radiation exposure during the operation harms the health of surgeons and patients. In addition, the accuracy of this surgery still needs to be improved. This study aimed to assess the radiation exposure and clinical efficacy of Tirobot-assisted vertebroplasty in treating thoracolumbar osteoporotic compression fracture.

Methods: Included in this retrospective cohort study were 60 patients (60-90 years) who had undergone unilateral vertebroplasty for thoracolumbar osteoporotic compression fracture at our hospital between June 2019 and June 2020. All showed no systemic diseases and were assigned to Tirobot group (treated with Tirobot-assisted approach) and control group (treated with traditional approach). Fluoroscopic frequency, operative duration, length of stay (LOS), post-operative complications (cement leakage, infection, and thrombosis), and pre-operative and predischarge indexes (VAS score, JOA score, and Cobb's angle) were compared.

Results: The fluoroscopic frequency $(P<0.001)$ and post-operative complications $(P=0.035)$ in Tirobot group were significantly lower than those in control group. The operative duration and LOS in the Tirobot group were shorter than those in the control group, but the differences were not statistically significant $(P=0.183)$. Pre-discharge VAS score and Cobb's angle decreased, and JOA increased after surgeries in both groups. These three indexes showed a significant difference after surgery in each group $(P<0.001)$, but not between groups $\left(P_{\text {VAS }}=0.175, P_{\text {cobb's }}=0.585, P_{\text {JOA }}=0.448\right)$.

Conclusion: The Tirobot-assisted vertebroplasty can reduce surgery-related trauma, post-operative complications, and patients' and operators' exposure to radiation. As a safe and effective strategy, this surgery can realize the quick recovery from thoracolumbar osteoporotic compression fracture.
\end{abstract}

Keywords: Compression fracture, Robot, Vertebroplasty

\footnotetext{
*Correspondence: lipeng_yu@aliyun.com; xiaojiancao001@163.com

${ }^{\dagger}$ Boyao Wang, Jiang Cao, and Jie Chang contributed equally to this work. Department of Orthopaedics, The First Affiliated Hospital of Nanjing Medical University, 300 Guangzhou Road, Nanjing 210029, Jiangsu, China
}

(C) The Author(s). 2021 Open Access This article is licensed under a Creative Commons Attribution 4.0 International License, which permits use, sharing, adaptation, distribution and reproduction in any medium or format, as long as you give appropriate credit to the original author(s) and the source, provide a link to the Creative Commons licence, and indicate if changes were made. The images or other third party material in this article are included in the article's Creative Commons licence, unless indicated otherwise in a credit line to the material. If material is not included in the article's Creative Commons licence and your intended use is not permitted by statutory regulation or exceeds the permitted use, you will need to obtain permission directly from the copyright holder. To view a copy of this licence, visit http://creativecommons.org/licenses/by/4.0/ The Creative Commons Public Domain Dedication waiver (http://creativecommons.org/publicdomain/zero/1.0/) applies to the data made available in this article, unless otherwise stated in a credit line to the data. 


\section{Introduction}

The incidence of thoracolumbar osteoporotic compression fracture keeps increasing in the elderly, often leading to low back pain, kyphosis, difficulty walking, and even neurological dysfunction [1,2]. Vertebroplasty, one of the traditional surgical methods to treat thoracolumbar fracture, is effective to relieve back pain and bed-rest complication [3-5]. In this surgery, however, both surgeons and patients may face a risk of dermatitis, cataract, and cancer, due to high-radiation exposure from repeated fluoroscopy [6-8]. Therefore, how to reduce the radiation dose of surgeons and patients, while ensuring the curative effect of the operation, is a problem needing urgent resolution.

Robotic surgery system has emerged as a major breakthrough in translational medicine (TM) [9]. As a representative, DaVinci robot-assisted system is being widely used in general surgery and urology, but rarely in orthopedic surgery. In recent years, many studies have reported the good performance of robots in joint surgery, such as total knee arthroplasty (TKA) and total hip arthroplasty (THA) [10, 11]. In addition, Tian et al. practiced Tirobot system in spinal surgery procedures, such as pedicle screw implantation, and achieved good results $[12,13]$. To date, however, there are insufficient reports on the application of robotic surgery system in percutaneous vertebroplasty.

In this study, the Tirobot system was used to perform vertebroplasty for osteoporotic thoracolumbar compression fracture. Meanwhile, its clinical efficacy and radiation on surgeons and patients were assessed.

\section{Materials and methods}

\section{Clinical data}

Between June 2019 and June 2020, we recruited 60 patients (27 males and 33 females, ages 61-89 years, mean $70(66,76)$ years $)$ receiving unilateral vertebroplasty for thoracolumbar osteoporotic compression fracture. The patients were averaged to Tirobot group (30 cases treated with Tirobot-assisted approach) and control group (30 cases treated with traditional approach). Unilateral percutaneous kyphoplasty (PKP) was performed to treat the lesion at T7-L5. An orthopedic robotic system (Tirobot) was introduced into the surgery in Tirobot group. The procedure was approved by the ethical committee of The First Affiliated Hospital of Nanjing Medical University.

\section{Orthopedic robotic system}

Tirobot is a system consisting of a reference tracker, a robotic arm, and a monitor. During the operation, the manipulator equipped with calibrator was placed at the operation site and aligned with the reference tracker. The $\mathrm{C}$-arm scanner was used to generate threedimensional images (Fig. 1). The data were loaded via calibrator automatically. The surgeon then planned the trajectory on axial, coronal, and sagittal planes (Fig. 2). The manipulator was adjusted according to the selected trajectory, till displaying the entry point and direction of the implant. A catheter was attached at the end of the robotic arm, allowing surgeons to implant bone cement or screws with the assistance of real-time navigation.

\section{Surgical procedures}

Except for surgical approaches, surgical instruments, and implants were the same in all operations. All interventions were performed by the same group formed by highly experienced surgeons.

\section{Control group}

After general anesthesia, the patient was placed in a prone position. The entry point of the needle was pinpointed by the mobile C-arm. After disinfection and dressing, an incision deep to the fascia was made. With fluoroscopic guidance, a puncture needle was inserted and propelled by a hammer to the posterior vertebral body. A biopsy sheath was inserted through the puncture needle to the anterior third of the vertebral body. After another round of fluoroscopic examination, a


Fig. 1 The base of the tracer in Tirobot system. a Traditional tracer base. $\mathbf{b}$ Self-made tracer base 

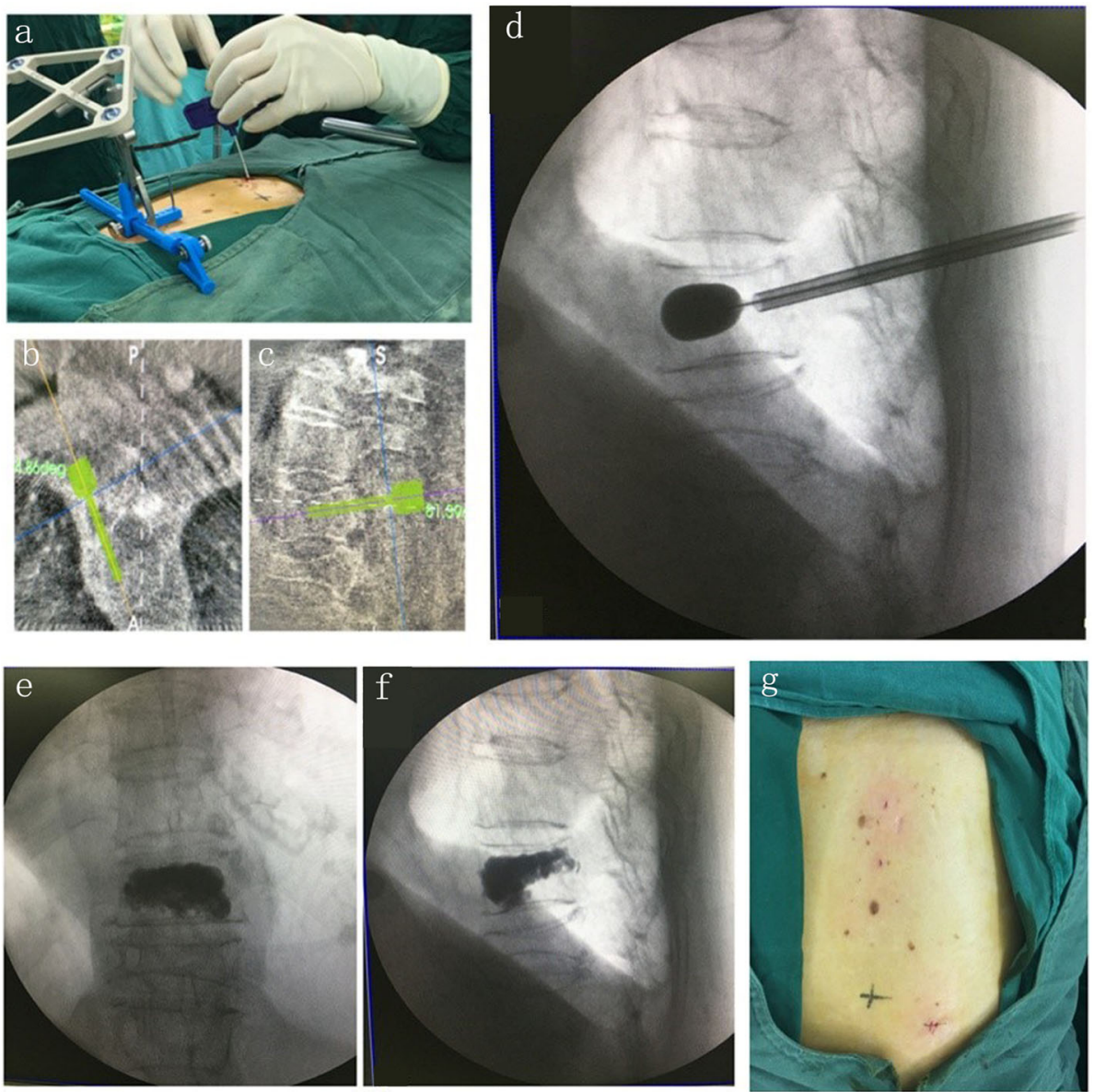

Fig. 2 Tirobot system surgical procedure. a Cement injection. b, c Trajectory planning. d Balloon placement. e, f Cement image. $\mathbf{g}$ Incision

reamer was used to make a hole in the vertebra, through which a balloon was placed into to create a void. Then, the bone cement was delivered into the void. After the third round of fluoroscopy, the sheath was removed. The incision was sutured and dressed up with aseptic bandages.

\section{Tirobot group}

After general anesthesia, the patient was fixed in a prone position, followed by disinfection and dressing. K-wire $(1.5 \mathrm{~mm})$ was used to connect the tracer and Tirobot system. Under fluoroscopic guidance, the images of lesions were collected. After image registration, the puncture point and angle were designed. Next, through manipulating Tirobot arms, the KMC (Kinetic Medical Co., Ltd) endoscope was targeted to the pedicle axis. An introducer needle $(1.6 \mathrm{~mm})$ was inserted through the endoscope. A 1.5-mm guide needle was inserted into the vertebral body through the pedicle, to the appropriate depth defined by fluoroscopy. A biopsy sheath was inserted through the biopsy needle, to the anterior third of the vertebral body height. After another round of fluoroscopic control, a reamer was used to make a hole in the vertebra, through which a balloon was placed into to create a void. Then, the bone cement was delivered into the void. After the third X-ray examination, the sheath was removed. The incision was sutured and dressed up with aseptic bandages.

\section{Postoperative care}

Pain and other vital signs were addressed. At the first day after the surgery, the patient was allowed to walk with a waist support. All the patients were discharged within postoperative 3 days and required to wear waist supports for 3 weeks and take routine anti-osteoporotic drugs continuously.

\section{Indexes}

Recorded were indexes about times of fluoroscopy, operative duration, LOS, complications, pre-operative and pre-discharge VAS score, JOA score, and Cobb's angle. The fluoroscopy was performed during incision positioning, puncture needle insertion, balloon expansion, and bone cement penetration in the control group. 
With the navigation of robotic arm, the fluoroscopy was not performed in the Tirobot group when the needle was being inserted.

Pre-operative VAS score and JOA score were collected before the use of pain-relievers. Cobb's angle between the most tilted upper and lower end of the vertebra was measured on a sagittal-plane radiograph with a semiautomated digital measurement system by an experienced doctor. The position of the cement was used to assess the accuracy of the operation. When the cement was completely placed in the vertebral body, the operation was considered as correct. When the cement leaked out of the vertebral body, the operation was considered incorrect.

\section{Statistical analysis}

SPSS 16.0 was used for statistical analysis. Measurement data were presented as mean \pm standard deviations and compared with $t$ test. The Mann-Whitney $U$ test was used to compare continuous variables that were not normally distributed and presented as medians and interquartile ranges. Enumeration data were presented as percentages and compared with chi-squared test. $P<$ 0.05 was considered as statistically significant.

\section{Results}

\section{Demographic data}

All the patients were DXA-diagnosed with osteoporosis. Operations were performed within 1 week after the fracture. Mild-trauma-caused compression fracture was found in the thoracic vertebra of 13 cases $(43.33 \%)$ and the lumbar vertebra of 17 cases $(56.67 \%)$ in the Tirobot group (14 males (46.67\%) and 16 females (53.33\%), ages $61-89$ years, mean $69.50(65.25,75.25)$ years $)$ and 12 cases $(40 \%)$ and 18 cases $(60 \%)$ in the control group (13 males (43.33\%) and 17 females (56.67\%), ages 61-86 years, mean $70(65.75,78.75)$ years $)$. No difference was found in T scores based on DXA: - $3.6 \pm 0.7$ in the Tirobot group and $-3.5 \pm 0.6$ in control group $(P=0.796)$. There was no significant difference in sex $(P=0.795)$ and age $(P=0.625)$ between both groups.

\section{Fluoroscopic times, operative duration, and LOS}

There was a significant difference in fluoroscopy times between both groups (Table 1). The control group

Table 1 Fluoroscopic frequency, operative duration, LOS in two groups

\begin{tabular}{llll}
\hline & $\begin{array}{l}\text { Tirobot group } \\
(\boldsymbol{n}=\mathbf{3 0 )}\end{array}$ & $\begin{array}{l}\text { Control group } \\
(\boldsymbol{n}=\mathbf{3 0})\end{array}$ & $\boldsymbol{P}$ value \\
\hline Fluoscopic frequency (times) & $9.80 \pm 1.74$ & $31.53 \pm 5.72$ & $<0.001$ \\
Operative duration (min) & $49.97 \pm 9.86$ & $48.27 \pm 15.51$ & 0.615 \\
LOS (days) & $1.7 \pm 0.84$ & $2.07 \pm 1.23$ & 0.183 \\
\hline
\end{tabular}

LOS length of stay underwent more times of radiographic evaluation than the Tirobot group $(31.53 \pm 5.72$ versus $9.80 \pm 1.74)$. Operative duration $(P=0.615)$ and $\operatorname{LOS}(P=0.183)$ were not significantly different.

\section{Postoperative complications}

As shown in Table 2, bone cement leakage was found in seven cases $(23 \%)$ in the control group (three of them developed neurological symptoms due to cement leakage) (Fig. 3) and none in Tirobot group. Two rates were different $(P=0.011)$. No other complications appeared, like infection and thrombosis.

\section{Pre-operative and pre-discharge VAS score, JOA score, and Cobb's angle}

Pre-discharge VAS score was lower than pre-operative VAS score in both groups. Each group showed intra-group difference $(P<0.05)$, but both showed no between-group difference $(P>0.05)$ (Table 3$)$. Pre-discharge JOA score was higher than pre-operative JOA score in both groups. Each group showed intra-group difference $(P<0.05)$, but both showed no between-group difference $(P>0.05)$ (Table 4$)$. Pre-discharge Cobb's angle was lower than pre-operative Cobb's angle in both groups. Each group showed intragroup difference $(P<0.05)$, but both showed no betweengroup difference $(P>0.05)$ (Table 5).

\section{Discussion}

Thoracolumbar vertebral compression fracture is common in patients with osteoporosis, especially postmenopausal women, with an estimated number of 3,750,000 cases in $2020[14,15]$. Previous studies have proved the superiority of vertebroplasty over conservative treatments [16-19]. However, in the former surgery, both patients and doctors face the damage from high radiation exposure, though protected by lead aprons, lead glasses, and lead gloves [6]. After 14 times of vertebroplasty, a surgeon may have received a radiation exposure that reaches the maximum one can endure during 1 year. However, a spine surgeon may accomplish more than 100 cases of vertebroplasty, indicating that excessive radiation exposure is common among spine surgeons [20,21].

Compared to manual procedures, robot-assisted implantation brings with less radiation exposure, more precise location and better prognosis in vertebroplasty.

Table 2 Postoperative complications in two groups

\begin{tabular}{lllll}
\hline & $\begin{array}{l}\text { Cement } \\
\text { leakage }\end{array}$ & $\begin{array}{l}\text { Leakage } \\
\text { rate }\end{array}$ & Infection & Thrombosis \\
\hline $\begin{array}{l}\text { Tirobot group } \\
(n=30)\end{array}$ & 0 & $0 \%$ & 0 & 0 \\
$\begin{array}{l}\text { Control group } \\
(n=30)\end{array}$ & 7 & $23 \%$ & 0 & 0 \\
$P$ value & $/$ & 0.011 & $/$ & $/$ \\
\hline
\end{tabular}




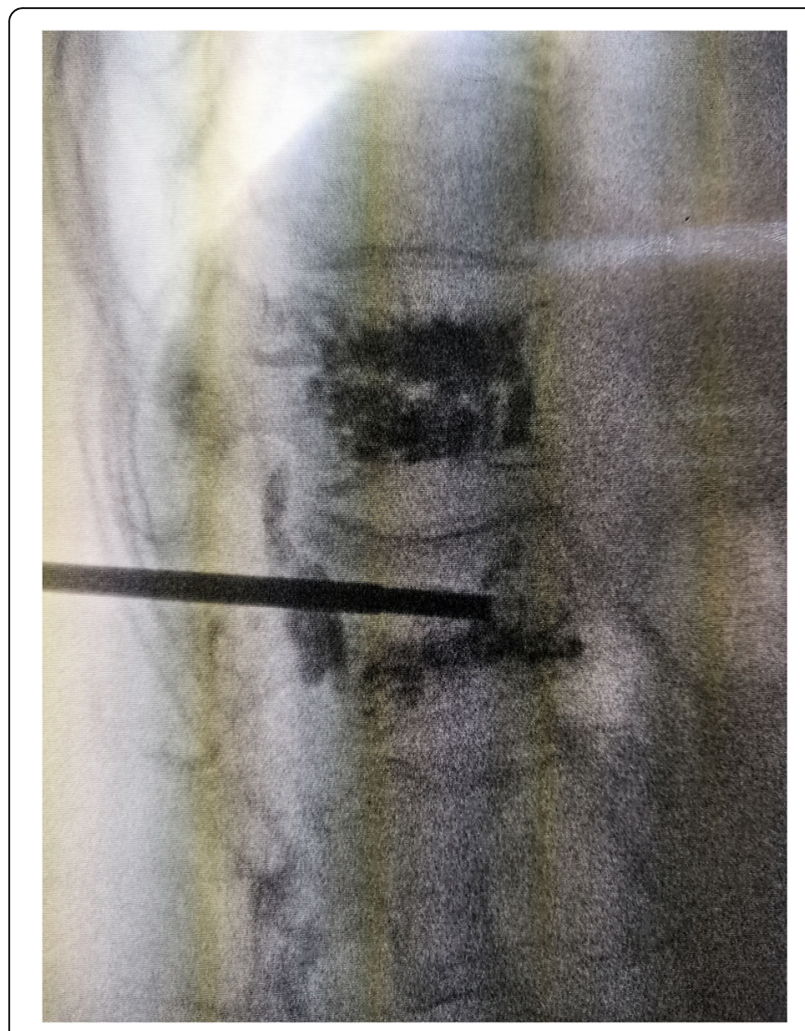

Fig. 3 Cement leakage. The cement was visible on the posterior vertebral edge. The cement in the upper centrum had been injected 1 year before this surgical intervention

Since 1992 in which a robotic system (Puma 260) was introduced into pedicle biopsy, robot-assisted vertebral surgeries have been revolutionized greatly [22]. Tirobot system, the third-generation orthopedic robot invented by Tian Wei [12], is being used at our hospital. With fluoroscopic guidance, the system displays high precision, good stability, minimal invasion, and reduced bleeding and radiation exposure $[23,24]$. During the operation, the surgeon can visualize the deep structure and the robot can finish pre-designed procedures. Therefore, we evaluated the advantages of Tirobot in vertebroplasty.

Compared to bilateral vertebroplasty, unilateral vertebroplasty consumes less time and leaves less trauma [25, 26]. The reason that we only tested the efficacy of Tirobot in the later is that the procedures in this surgery, like

Table 3 Pre-operative and pre-discharge VAS scores in two groups

\begin{tabular}{llll}
\hline & Pre-operative & Pre-discharge & $\boldsymbol{P}$ value \\
\hline Tirobot group $(n=30)$ & $8.100 \pm 1.062$ & $2.700 \pm 1.21$ & $<0.001$ \\
Control group $(n=30)$ & $8.300 \pm 0.915$ & $3.067 \pm 0.823$ & $<0.001$ \\
$P$ value & 0.438 & 0.175 & \\
\hline
\end{tabular}

VAS visual analog scale
Table 4 Pre-operative and pre-discharge JOA scores in two groups

\begin{tabular}{llll}
\hline & Pre-operative & Pre-discharge & $P$ value \\
\hline Tirobot group $(n=30)$ & $15.13 \pm 2.50$ & $23.33 \pm 2.47$ & $<0.001$ \\
Control group $(n=30)$ & $16.47 \pm 3.16$ & $23.97 \pm 3.80$ & $<0.001$ \\
$P$ value & 0.075 & 0.448 & \\
\hline
\end{tabular}

JOA Japanese orthopaedic association scores

pinpointing entry point of the needle, should be performed with high-precision biopsy and can be resolved by a robot. Besides, between the two modes of vertebroplasty, PKP has higher safety and better prognosis than percutaneous vertebroplasty (PVP) [27-29]. In clinical practice, PVP needs less time. Therefore, we applied Tirobot system in PKP, which is more suitable to test the usefulness of Tirobot in reducing operative duration.

Few reports about robot-assisted vertebroplasty have been published, indicating the difficulty in widening its application. In the operation, the tracer of the robot must be fixed, and especially during the implantation, the tracer must be tightly fastened to the spinous process. To realize this, however, the process must be totally exposed in prior, through which the skin and muscles have to be cut apart. Therefore, robot-assisted vertebroplasty brings more surgical wounds, thus greatly restricting its wide use. To solve this problem, we improved the Tirobot by introducing a base fixed with 1 to $3 \mathrm{~K}$-wires, thereby avoiding the additional surgical incision. In using the new Tirobot system, the base of the tracer was stable and simple and the operation was less laborious (Fig. 1). Our technical innovation paves the way to the wide replication of robot-assisted vertebroplasty.

It is easy to fix the tracer to the lumbar process through vertically drilling with two K-wires $(1.5 \mathrm{~mm})$, but difficult when the process is narrow. We have tested the thickness of the processes in different vertebrae. The thickness reaches its maximum in $\mathrm{T} 1$ and minimum in T7: $\mathrm{T} 1>\mathrm{T} 12>\mathrm{T} 2>\mathrm{T} 11>\mathrm{T} 10>\mathrm{T} 3>\mathrm{T} 9>\mathrm{T} 4>\mathrm{T} 5>\mathrm{T} 8>\mathrm{T} 6>\mathrm{T} 7$. The processes of $\mathrm{T} 3-\mathrm{T} 9$ are all $<5 \mathrm{~mm}$ in thickness. Clinically, a process $<5 \mathrm{~mm}$ in thickness is hard to be fixed with the K-wire. Therefore, in fixing the tracer to T3-T9, we did not drill into the process from a direction vertical to its surface, but from a bevel direction (sometime supported by another K-wire). With this method,

Table 5 Pre-operative and pre-discharge Cobb's angles in two groups

\begin{tabular}{llll}
\hline & Pre-operative & Pre-discharge & $P$ value \\
\hline Tirobot group $(n=30)$ & $21.72 \pm 2.85$ & $10.54 \pm 1.77$ & $<0.001$ \\
Control group $(n=30)$ & $20.80 \pm 3.17$ & $10.87 \pm 2.83$ & $<0.001$ \\
$P$ value & 0.244 & 0.585 & \\
\hline
\end{tabular}


all the tracer bases were implanted in one setting, avoiding the use of fluoroscopy.

In this study, the Tirobot-assisted vertebroplasty achieved favorable outcomes, as shown by its high precision (precision $<1 \mathrm{~mm}$ ) and safety [12]. All the biopsy procedures were accomplished in one setting. In the control group, however, the entry point and the needle direction had to be adjusted repeatedly under fluoroscopic guidance, thus increasing the operative duration and radiation exposure. Besides, in Tirobot-assisted vertebroplasty, the surgeon could make punctures from a wider range of angles. Consequently, the balloon could be well deflated, and cement injected into the right center of the vertebral body (Fig. 2). An ideal injection point can promote the distribution and reduce the leakage of bone cement and prevent the post-operative stressinduced fracture. In the present study, the results of cement leakage was not consistent with other studies $[28,30,31]$. This may be explained by the different evaluation criteria and the small size of clinical samples included in this study. We also found more favorable Cobb's angle, complication rate, VAS, and JOA in Tirobot-assisted vertebroplasty. A shorter LOS also indicated the possibility of enhanced recovery after surgery (ERAS).

Limitations also exist in this study. First, the follow-up is short; long-term clinical observation is needed to evaluate the efficacy of Tirobot-assisted vertebroplasty. Second, the sample size is small. The insignificant difference in LOS and operative duration may arise from the scarcity of the samples. In future studies, we will prolong the follow-up time and increase the sample size to make the results more convincing. Supplementary explanation has been added in the article.

\section{Conclusion}

Tirobot-assisted vertebroplasty can reduce surgery-related trauma, post-operative complications, and patients' and operators' exposure to radiation. As a safe and effective strategy, this technique can realize the quick recovery from thoracolumbar osteoporotic compression fracture.

\section{Abbreviations}

PKP: Percutaneous kyphoplasty; PVP: Percutaneous vertebroplasty; ERAS: Enhanced recovery after surgery; LOS: Length of stay; KMC: Kinetic Medical Co., Ltd; TM: Translational medicine; TKA: Total knee arthroplasty; THA: Total hip arthroplasty

\section{Acknowledgements}

Not applicable.

\section{Authors' contributions}

Xiaojian Cao, Lipeng Yu, Guoyong Yin, Weihua Cai, Qingqing Li, and Zhenfei Huang contributed to the conception and design of the study. Boyao Wang and Jiang Cao contributed to the acquisition of the data. Jiang Cao and Jie Chang contributed to the analysis and interpretation of the data. Boyao Wang and Jie Chang contributed to the drafting of the manuscripts. Xiaojian Cao and Lipeng Yu were responsible for the critical revision of the manuscript for important intellectual content. The authors read and approved the final manuscript.

\section{Funding}

This work was supported by the National Natural Science Foundation of China (Grant \#81672152, 81871773). The authors declare that they have no conflict of interest.

\section{Availability of data and materials}

All data generated during this study are included in this published article.

\section{Ethics approval and consent to participate}

All subjects signed informed consent by each patient. The procedure was approved by the ethical committee of The First Affiliated Hospital of Nanjing Medical University.

\section{Consent for publication}

Not applicable.

\section{Competing interests}

The authors declare that they have no conflict of interest.

Received: 25 November 2020 Accepted: 5 January 2021

Published online: 19 January 2021

\section{References}

1. Patil S, Rawall S, Singh D, Mohan K, Nagad P, Shial B, et al. Surgical patterns in osteoporotic vertebral compression fractures. Eur Spine J. 2013;22(4):883-91.

2. Old $J \mathrm{~L}$, Calvert M. Vertebral compression fractures in the elderly. Am Fam Physician. 2004;69(1):111-6.

3. Jay B, Ahn SH. Vertebroplasty. Semin Interv Radiol. 2013;30(3):297-306.

4. Buchbinder R, Johnston RV, Rischin KJ, Homik J, Jones CA, Golmohammadi $\mathrm{K}$, et al. Percutaneous vertebroplasty for osteoporotic vertebral compression fracture. Cochrane Database Syst Rev. 2018;4(4):Cd006349.

5. Filippiadis DK, Marcia S, Masala S, Deschamps F, Kelekis A. Percutaneous vertebroplasty and kyphoplasty: current status, new developments and old controversies. Cardiovasc Intervent Radiol. 2017;40(12):1815-23.

6. Loisel F, Menu G, Boyer E, Pluvy I, Obert L. Radiation exposure and the orthopedic surgeon's hand: measurement of the equivalent dose over 13 months. Hand Surg Rehabil. 2017;36(2):97-101.

7. Mroz TE, Abdullah KG, Steinmetz MP, Klineberg EO, Lieberman IH. Radiation exposure to the surgeon during percutaneous pedicle screw placement. J Spinal Disord Tech. 2011;24(4):264-7.

8. Harrison Farber S, Nayar G, Desai R, Reiser EW, Byrd SA, Chi D, et al Radiation exposure to the surgeon during minimally invasive spine procedures is directly estimated by patient dose. Eur Spine J. 2018; 27(8):1911-7.

9. Mediouni M, Madiouni R, Gardner M, Vaughan N. Translational medicine: challenges and new orthopaedic vision (Mediouni-Model). Curr Orthop Pract. 2019;31(2):1.

10. Abdelfadeel W, Houston N, Star A, Saxena A, Hozack WJJB, Journal J. CT planning studies for robotic total knee arthroplasty: what does it cost and does it require a formal radiologist reporting? Bone and Joint J. 2020;102-B(6 Supple_A):79-84.

11. Domb BG, Chen JW, Lall AC, Perets I, Maldonado DR. Minimum 5-year outcomes of robotic-assisted primary total hip arthroplasty with a nested comparison against manual primary total hip arthroplasty: a propensity score-matched study. J Am Acad Orthop Surg. 2020;28(20):847-56.

12. Tian W. Robot-assisted posterior C1-2 transarticular screw fixation for atlantoaxial instability: a case report. Spine (Phila Pa 1976). 2016:41(Suppl 19):B2-b5.

13. Zhang $Q$, Han XG, Xu YF, Fan MX, Zhao JW, Liu YJ, et al. Robotic navigation during spine surgery. Expert Rev Med Devices. 2020;17(1):27-32.

14. Wood KB, Li W, Lebl DR, Ploumis A. Management of thoracolumbar spine fractures. Spine J. 2014;14(1):145-64.

15. Kaye JJ, Nance EP Jr. Thoracic and lumbar spine trauma. Radiol Clin N Am. 1990;28(2):361-77.

16. Yuan WH, Hsu HC, Lai KL. Vertebroplasty and balloon kyphoplasty versus conservative treatment for osteoporotic vertebral compression fractures: a meta-analysis. Medicine (Baltimore). 2016;95(31):e4491. 
17. Zuo XH, Zhu XP, Bao HG, Xu CJ, Chen H, Gao XZ, et al. Network metaanalysis of percutaneous vertebroplasty, percutaneous kyphoplasty, nerve block, and conservative treatment for nonsurgery options of acute/subacute and chronic osteoporotic vertebral compression fractures (OVCFs) in shortterm and long-term effects. Medicine (Baltimore). 2018;97(29):e11544.

18. Mattie R, Laimi K, Saltychev SYM. Comparing percutaneous vertebroplasty and conservative therapy for treating osteoporotic compression fractures in the thoracic and lumbar spine: a systematic review and meta-analysis. J Bone Joint Surg Am. 2016;98(12):1041-51.

19. Xie L, Zhao ZG, Zhang SJ, Hu YB. Percutaneous vertebroplasty versus conservative treatment for osteoporotic vertebral compression fractures: an updated meta-analysis of prospective randomized controlled trials. Int J Surg. 2017:47:25-32

20. Urakov TM. Practical assessment of radiation exposure in spine surgery. World Neurosurg. 2018:120:e752-4.

21. Srinivasan $\mathrm{D}$, Than $\mathrm{KD}$, Wang AC, La Marca F, Wang Pl, Schermerhorn TC, et al. Radiation safety and spine surgery: systematic review of exposure limits and methods to minimize radiation exposure. World Neurosurg. 2014; 82(6):1337-43.

22. Lavallée S, Sautot P, Troccaz J, Cinquin P, Merloz P. Computer-assisted spine surgery: a technique for accurate transpedicular screw fixation using CT data and a 3-D optical localizer. J Image Guid Surg. 1995:1 (1):65-73.

23. Le X, Tian W, Shi Z, Han X, Liu Y, Liu B, et al. Robot-assisted versus fluoroscopy-assisted cortical bone trajectory screw instrumentation in lumbar spinal surgery: a matched-cohort comparison. World Neurosurg. 2018;120:e745-51

24. Long T, Li KN, Gao JH, Liu TH, Mu JS, Wang XJ, et al. Comparative study of percutaneous sacroiliac screw with or without tirobot assistance for treating pelvic posterior ring fractures. Orthop Surg. 2019;11(3):386-96.

25. Chang W, Zhang $X$, Jiao N, Yuwen P, Zhu Y, Zhang F, et al. Unilateral versus bilateral percutaneous kyphoplasty for osteoporotic vertebral compression fractures: a meta-analysis. Medicine (Baltimore). 2017;96(17):e6738.

26. Huang Z, Wan S, Ning L, Han S. Is unilateral kyphoplasty as effective and safe as bilateral kyphoplasties for osteoporotic vertebral compression fractures? A meta-analysis. Clin Orthop Relat Res. 2014;472(9):2833-42.

27. Wang $\mathrm{S}$, Wang $\mathrm{H}$, Niu L. Clinical efficacy of PVP and PKP in the treatment of OVCFs after bilateral resection of ovarian cancer. Oncol Lett. 2018:16(1):151-6.

28. Wang H, Sribastav SS, Ye F, Yang C, Wang J, Liu H, et al. Comparison of percutaneous vertebroplasty and balloon kyphoplasty for the treatment of single level vertebral compression fractures: a meta-analysis of the literature. Pain Physician. 2015;18(3):209-22.

29. Hu KZ, Chen SC, Xu L. Comparison of percutaneous balloon dilation kyphoplasty and percutaneous vertebroplasty in treatment for thoracolumbar vertebral compression fractures. Eur Rev Med Pharmacol Sci. 2018;22(1 Suppl):96-102.

30. Zhan Y, Jiang J, Liao H, Tan H, Yang K. Risk factors for cement leakage after vertebroplasty or kyphoplasty: a meta-analysis of published evidence. World Neurosurg. 2017;101:633-42.

31. Riesner HJ, Kiupel K, Lang P, Stuby F, Friemert B, Palm HG. Clinical relevance of cement leakage after radiofrequency kyphoplasty vs. balloon kyphoplasty: a prospective randomised study. Z Orthop Unfall. 2016;154(4):370-6.

\section{Publisher's Note}

Springer Nature remains neutral with regard to jurisdictional claims in published maps and institutional affiliations.

Ready to submit your research? Choose BMC and benefit from:

- fast, convenient online submission

- thorough peer review by experienced researchers in your field

- rapid publication on acceptance

- support for research data, including large and complex data types

- gold Open Access which fosters wider collaboration and increased citations

- maximum visibility for your research: over $100 \mathrm{M}$ website views per year

At BMC, research is always in progress.

Learn more biomedcentral.com/submissions 